\title{
Application of pixantrone in a III line of treatment as a bridge therapy to allotransplantation of stem cells
}

Anna Kwiatkowska-Pamuła, Aleksandra Janeczek, Sebastian Giebel

Department of Bone Marrow Transplantation and Oncohematology,

Maria Sklodowska Curie National Research Institute of Oncology,

Gliwice, Poland

Correspondence:

Anna Kwiatkowska-Pamuła,

Aleksandra Janeczek

Department of Bone Marrow

Transplantation and Oncohematology,

Maria Sklodowska Curie National

Research Institute of Oncology,

Gliwice Branch,

44-101 Gliwice,

Wybrzeże Armii Krajowej 15 tel.: (32) $2788886,(32) 2788887$

fax: (32) 2313512

Received:

4.06.2020

Accepted:

30.06.2020

DOI: 10.24292/01.OR.220300620.4

\section{ABSTRACT}

Diffuse large B-cell lymphomas are the most common group among all lymphomas. Despite the effectiveness of the I line therapy in $10-40 \%$ of patients, the possibility of relapse should be taken into account. The anthracycline antibiotics used in the II line therapy carry a high risk of cardiac complications. In patients with refractory or recurrent disease, emergency treatment is used, aiming for the transplantation of hematopoietic cells. If the II line therapy fails, the prognosis is bad. A new chance for patients with refractory or recurrent B-cell lymphoma is pixantrone dimaleate, a drug structurally related to anthracyclines with a significantly lower cardiotoxic potential.

The paper presents a case of a 65-year-old patient with relapsing DLBCL lymphoma, after two treatment lines: R-CHOP and R-DHAP, and after autologous transplantation of stem cells, in which the use of pixantrone in the treatment of recurrence allowed to achieve remission and prepare the patient for the allo-HSCT procedure.

Key words: pixantrone, DLBCL lymphoma, chemotherapy, cardiotoxicity, allo-HSCT 


\section{INTRODUCTION}

Diffuse large B-cell lymphoma (DLBCL) belong to non-Hodgkin lymphoma accounting for about $80 \%$ of cases among aggressive lymphomas. The incidence of DLBCL lymphoma in Europe is estimated for about several cases per year per 100,000 general population for a year [1]. I line treatment is based on the use of anthracycline and anti-CD20 antibodies [2]. Currently, immunochemotherapy according to the R-CHOP-21 (rituximab, cyclophosphamide, doxorubicin, vincristine, prednisone) scheme is used [3].

The remission rate obtained after I line treatment is $65-70 \%$ [2]. Despite the high effectiveness of I line immunochemotherapy, approximately $10-40 \%$ of patients (depending on their prognostic factors) are at the risk of relapse [1]. The use of doxorubicin carries the risk of complications associated with the cardiotoxicity of anthracycline antibiotics. The mechanism of combining these drugs with the cardiolipin presented in the inner mitochondrial membrane results in a disruption of the structure and function of mitochondria. Free radicals produced during this process lead to disturbance of protective mechanisms dependent on peroxide dismutase, catalase and glutathione peroxidase. The anthracycline antibiotics cause impaired of function sodium-potassium pump resulting in the accumulation of potassium ions in cardiomyocytes and secondary cardiac arrhythmias. Calcium ion accumulation in cardiomyocytes associated with anthracyclines leads to damage and necrosis of myocardial fibres [4]. An important mechanism that induces the cardiotoxic effect of doxorubicin is associated with iron metabolism caused by its metabolites-free radicals and secondary alcohol (doxorubicinol) [5]. After anthracycline treatment, the risk of developing congestive heart failure is estimated at $16 \%$. At the same time, the risk of developing asymptomatic cardiomyopathy is up to $57 \%$ [6]. The development of post-anthracycline cardiomyopathy is influenced by factors such as previous mediastinal radiation, age $>65$ years, heart disease, hypertension, diabetes, liver disease and genetically determined diseases (e.g. Down syndrome) [4].

In patients aged under 65-70 years with refractory or relapsed lymphoma, without major organ dysfunction, II line rescue therapy based on R-DHAP (rituximab, cisplatin, cytarabine, dexamethasone), R-ICE (rituximab, ifosfamide, carboplatin, etoposide), R-GDP (rituximab, cisplatin, gemcitabine, dexamethasone) schemes is included. After obtaining a response with prior highdose consolidation chemotherapy, the autologous hematopoietic stem cell transplantation (auto-HSCT) should be incorporated. In the case of relapse after auto-HSCT, the patient's qualification for allogeneic/haploidentical HSCT is considered [3].
In the case of patients who are not candidates for auto-HSCT or whose relapse appeared after II line treatment, the prognosis is poor with the predicted survival time of about 6 months [7]

Pixantrone dimaleate is a new opportunity in the III and IV line of treatment for patients with refractory and relapsed B-cell non-Hodgkin lymphoma. Pixantrone is a drug belonging to the azaantracenediones, structurally related to anthracyclines and anthracenediones [8]. Unlike these chemotherapeutics, it is a weak topoisomerase II inhibitor. The drug directly alkylates DNA. Pixantrone, by creating permanent bonds with the DNA helix, leads to its breakage. Lack of ketone groups and incorporation of a nitrogen heteroatom into the ring result in a lower ability to form reactive oxygen species, iron binding and the production of alcohol metabolites responsible for the cardiotoxic effect of classic anthracyclines [9]. The efficacy of pixantrone as a monotherapy used in patients with refractory or relapsed non-Hodgkin lymphoma has been demonstrated in an open, international, randomized study phase III (PIX301). In the group of patients treated with pixantrone, a significantly higher percentage of the overall response to treatment was demonstrated compared to the group treated with the comparator monotherapy (vinorelbine, oxaliplatin, ifosfamide, etoposide, mitoxatron or gemcitabine). The percentage of complete response (CR) among patients treated with pixantrone was $20 \%$. In comparison, in the comparator-treated group CR was obtained in 5.7\%. A longer progression-free survival and overall survival was also demonstrated in patients treated with pixantrone [10]. The most common side effects of the drug are associated with bone marrow suppression (especially the risk of neutropenia), nausea and weakness. The drug is used at a dose of $50 \mathrm{mg} / \mathrm{m}^{2}$ on $1^{\text {st }}, 8^{\text {th }}$ on the $15^{\text {th }}$ day of the 28 -day cycle. Treatment is continued for up to 6 cycles [9]. In Poland, pixantrone dimaleate is refunded in the drug program for the treatment of non-Hodgkin lymphoma. The drug is intended for use in the III and IV line of treatment of patients with refractory and relapsed B-cell non-Hodgkin lymphoma who have had a prior sustained response (complete or partial) to anthracyclines or anthracenedione [11].

This paper presents the case of a 65 -year-old patient with relapsed DLBCL lymphoma treated in the Bone Marrow Transplantation and Oncohematology Clinic. The patient underwent therapy with two lines: R-CHOP and R-DHAP, and additionally auto-HSCT. The use of pixantrone in the relapse allowed to achieve disease remission and preparation for the allo-HSCT procedure.

\section{CASE PRESENTATION}

In October 2014, the described patient showed focal spleen changes and abdominal lymphadenopathy on ultrasound. In this 
situation the patient underwent splenectomy, and histopathological examination showed diffuse large B-cell lymphoma (DLBCL) with the presence of $\mathrm{CD} 20+++$ and $\mathrm{Ki}-67>90 \%$.

On the basis of diagnostic tests, DLBCL lymphoma in stage CS III with IPI 2 was established and the patient was qualified for the I line treatment. By May 2015, the patient had received a total of eight R-CHOP cycles at the Hematology Department in Częstochowa, with a remission described in the documentation as $\mathrm{CRu}$ (unconfirmed complete remission). Control PET-CT performed in November 2015, showed residual disease in the lymph nodes on both sides of the diaphragm. Due to the coexistence of hyperthyroidism in the course of nodular goiter and the need for strumectomy, the patient was left for observation within the Hematological Clinic.

In August 2016, the PET examination detected features of relapsed lymphoma in individual supra-and diaphragmatic lymph nodes. The patient was qualified for the II line treatment using immunochemotherapy in the R-DHAP regimen. After two cycles, complete remission (CR2) was obtained, confirmed in PET-CT January $2^{\text {nd }}, 2017$. Due to the recurrent nature of the disease, the patient was qualified for auto-HSCT. In March, after conditioning treatment based on the BeBEAM scheme, the auto-HSCT procedure was performed.

The PET-CT reassessment was performed as part of the outpatient control in June 2017 with an oncologically negative result. The patient was under outpatient control of the Hematology Outpatient Clinic with mild stable anemia during subsequent visits, without any general symptoms.

In April 2018, a control PET-CT examination was performed, in which the focal points of radiolabel uptake in the projection of cervical, axillary and retroperitoneal lymph nodes with SUV max from 5.3 to 11.4 and sizes up to $20 \mathrm{~mm}$ in the long axis were revealed, which suggested relapse of lymphoma.

In order to monitor the disease progression, the ultrasound check of neck lymph nodes was performed in May 2018, showing enlarged lymph nodes of ambiguous nature in groups IIA and IIB and $V$ in the long axis up to $27 \mathrm{~mm}$. In addition, bone marrow cytometry was performed, where a complete lack of $B$ lymphocytes was present, which excluded the involvement of the bone marrow by DLBCL lymphoma and $34 \%$ of T cells and $66 \%$ of NK cells.

In August 2018, the patient was admitted to the Transplant and Oncohematology Clinic of the Oncology Center-Institute in Gli- wice where comprehensive diagnostics was carried out to assess disease progression. Histopathologically re-evaluated preparations obtained during splenectomy in 2014, revealed: diffuse large B-cell lymphoma NOS, germinal center B-cell subtype with the phenotype: CD20+, MYC-, BCL2-, BCL6+, CD10+/-, MUM1-, CD21-/+, CD3-, CD5-, CD23-, CD30-, CD138-, cyclin D1-, EBV LMP1-, Ki67 proliferative activity $70 \%$.

Peripheral blood cytometry showed: $65 \%$ of lymphocytes, among which: $2.4 \%$ of B lymphocytes with the phenotype: CD45 high/int CD19+ CD20+, of which $27 \%$ of CD10+. Light chain cloning on the surface of B lymphocytes: $55 \%$ kappa vs $45 \%$ lambda; $40 \%$ T-cells and $52 \%$ NK cells. The bone marrow trepanobiopsy showed no signs of fibrosis, $30 \%$ cellularity with the presence of three haematopoietic lines with preserved maturation without lymphoma infiltration

After analyzing the clinical data, taking into account the previous sustained response after anthracycline treatment lasting over 6 months, the patient was qualified for treatment of III line according to the drug program for the treatment of malignant lymphomas using pixantrone.

Transthoracic echocardiography (TTE) performed before implementing the treatment showed left ventricular ejection fraction (LVEF) - 54\%, the presence of a trace of the reversal wave to the left atrium, no pericardial changes, and correct measurements of cardiac chambers. No regional wall motion abnormalities were found.

The echocardiographic evaluation made after two cycles of treatment revealed EF 50\% without disturbances in myocardial contractility and other dysfunctions. Simultaneous lymph node control ultrasound showed enlarged neck lymph nodes in regions previously described as positive in PET-CT with maximal size up to $11 \mathrm{~mm}$, without no enlargement of other groups of peripheral nodes and no abdominal lymphadenopathy.

Control cytometry from peripheral blood and bone marrow showed no involvement by DLBCL lymphoma.

After three cycles of treatment in PET-CT, compared to the previous study from April $10^{\text {th }}, 2018$, complete remission of the nodal over and under the diaphragm was found. Two new lesions of focal nature in the larynx on the left side and in the right lobe of the prostate after specialist evaluation and consultation of laryngology and urology without oncological significance were subjected to further observation. 
During pixantrone treatment, no decrease in granulocytes requiring temporary chemotherapy delay, arrhythmias or cardiac events was observed. The patient was administered granulocyte colony-stimulating factor (G-CSF) filgrastim - in the dosage of: 48 million units (MU) for 3 days - 24 hours after using the medicine on the $1^{\text {st }}$ and $8^{\text {th }}$ day and for 7 days -24 hours after using the medicine on $15^{\text {th }}$ day. The patient did not require any blood transfusions during therapy. The only side effect that the patient noticed was bluish skin. Treatment was completed in October 2018, after a fourth cycle (incomplete - no dose of $15^{\text {th }}$ day), followed by recurrent upper respiratory tract infections requiring repeated antibiotic therapy, and moderate anemia and thrombocytopenia above $100 \mathrm{~K} / \mu \mathrm{l}$.

In December 2018, the patient underwent diagnostic tests assessing the treatment. In bone marrow cytology, erythroblastic depletion and small dysplasia in the granuloblastic and erythroblastic system were found, exceeding $10 \%$ of the cells. In trepanobiopsy: approximately $25 \%$ cellularity with first degree fibrosis, without signs of B-cell lymphoma infiltration. In control PET-CT no pathological radiolabel uptake foci corresponding to tumor lesions with high glucose metabolism were observed. Due to persistent remission, the patient was qualified for allo-HSCT. The patient does not have a compatible related donor, and currently an unrelated donor is being searched.

\section{DISCUSSION}

The presence of adverse risk factors in patients with DLBCL lymphoma increases the likelihood of relapse. The number of combirdites, the intensity of the I line treatment as well as the patient's age are also an important factors. The presence of high risk, the use of more intensive than the standard $\mathrm{R}-\mathrm{CHOP}$ regimen treatment in the I line increases the risk of recurrence to $30-35 \%$ while the age above 60 years even to $40 \%$ [12]. Among the unfavorable prognostic factors the presence of $M Y C$ gene rearrangement and a correlation with the extra-nodal location of the disease including in the central nervous system is attributed. At this point, the double rearrangement of the MYC and BCL2 genes, also known as the double hit, often accompanied by additional translocation of the BCL6 gene (triple strike) should also be mentioned. Double and triple hit changes occur in approximately $5 \%$ of patients and are associated with very poor prognosis and shortening of survival time to approx. 8 months [13]. These variables did not occur in the described case.

One should also mention the phenomenon of multi-drug resistance, which is one of the main causes of therapy failures, and is associated with both pharmacological factors such as incorrect dosage, changes in metabolism or bioavailability of the drug, as well as with cellular factors conditioned among others from transport proteins (in the case of anthracycline, from P-glycoprotein) [14]. The effectiveness of pixantrone remission occurs in patients with multi-drug resistance. Abolition of the multi-drug resistance is the result of a different mechanism of action on the DNA of cancer cells compared to classic anthracyclines [15].

The most common toxic effect of pixantrone is neutropenia due to bone marrow suppression. Patients experienced severe infections while using the drug, but their incidence was around $6 \%$ in the PIX301 study group and no opportunistic infections associated with neutropenia were observed in the registration study [10].

Cardiotoxic effect in the course of oncological therapy appears not only with the use of anthracyclines, but also alkylating drugs, Vinca alkaloids, paclitaxel, mitomycin, bleomycin, fluorouracil, interferons, monoclonal antibodies and tyrosine kinase inhibitors. The use of oncological treatment is one of the most common causes of heart failure [4]. Polychemotherapy often includes several substances that have an adverse effect on the heart muscle, which is why it is so important to choose treatment in the next line with a better cardiological profile. Pixantrone, while maintaining the anti-tumor activity of anthracyclines, also has less potential for cardiotoxic mechanisms associated with the generation of oxygen free radicals, binding to iron and the formation of harmful alcohols $[10,16]$. Substitution of pixantrone in the R-CHOP scheme in place of doxorubicin (R-CPOP) resulted in a decrease in toxicity without changing antitumor activity [17]. Heart failure observed during pixantrone treatment did not increase with the length of drug treatment, and its course was often asymptomatic or in grade first and second [10].

Relapsed or refractory patients with prior responses to anthracyclines who received pixantrone achieved better results in overall survival, response rate, and progression-free time compared to other chemotherapeutic agents (PIX301 study). Patients who received previous rituximab regimens benefit more from treatment than patients who did not use monoclonal antibody [18].

The use of allogeneic stem cell transplantation and the occurrence of a graft-versus-leukemia $(\mathrm{GvL})$ reaction provides recovery in relapsed or refractory patients who have achieved partial or transient therapeutic effects. In the case of DLBCL lymphoma, the results of long-term remission after allo-HSCT are worse than in patients with peripheral T-cell lymphoma (PTCL) or follicular lymphoma (FL). Relapses in these patients most often appear 
one year after transplantation, which is associated with a lower significance of GvL reactions. Thus, patients with relapse after auto-HSCT are eligible for allo-HSCT in DLBCL lymphoma, and the most important factor affecting the distant results of transplantation is obtaining remission before the procedure $[19,20]$.

\section{SUMMARY}

The search for therapies with a better cardiological profile in DLBCL lymphoma is crucial for the long-term assessment of the patient's quality of life. Pixantrone treatment according to literature data and on the basis of case studies carried out, not only involves good treatment tolerance and lower cardiological toxicity, but allows achieving remission in relapsed patients and consolidation supported by allogeneic stem cell transplantation.

\section{References}

1. Warzocha K. Chłoniak rozlany z dużych komórek B. In: Robak T, Warzocha K. Hematologia. Gdańsk 2016: 956-80.

2. Appio L, Landoni C, La Targia M. Single-agent pixantrone as a bridge to autologous stem cell transplantation in a patient with refractory diffuse large B-cell lymphoma. Chemotherapy. 2017; 62(3): 187-91.

3. Tilly $\mathrm{H}$, Gomes da Silva M, Vitolo U. Diffuse large B-cell lymphoma (DLBCL): ESMO clinical practice guidelines for diagnosis, treatment and follow-up. Ann Oncol. 2015; 26(Suppl 5): v116-25. http://doi.org/10.1093/annonc/mdv304.

4. Piętka I, Lelonek M. Kardiomyopatia poantracyklinowa - diagnostyka, leczenie i zapobieganie. Folia Cardiologica Excerpta. $2010 ;$ 5(3): 130-4.

5. Minotti G, Ronchi R, Salvatorelli E et al. Doxorubicin irreversibly inactivates iron regulatory proteins 1 and 2 in cardiomyocytes: evidence for distinct metabolic pathways and implications for iron-mediated cardiotoxicity of antitumor therapy. Cancer Res. 2001; 61(3): 8422-8.

6. Dudziak J, Słomczyński M, Torliński L. Powikłania kardiologiczne po chemioterapii - patomechanizm, diagnostyka, leczenie i zapobieganie. Choroby Serca i Naczyń. 2009; 6(2): 73-9.

7. Chao MP. Treatment challenges in the management of relapsed or refractory non-Hodgkin's lymphoma - novel and emerging therapies. Cancer Manag Res. 2013; 5: 251-69.

8. Boyle EM, Morschhauser F. Pixantrone: a novel anthracycline-like drug for the treatment of non-Hodgkin lymphoma. Expert Opinon on Drug Safety. 2015; 14(4): 601-17.

9. The European Medicines Agency review of pixantrone for the treatment of adult patients with multiply relapsed or refractory aggressive non-Hodgkin's B-cell lymphomas: summary of the scientific assessment of the committee for medicinal products for human use. Oncologist. 2013; 18(5): 625-33.

10. Pettengell R, Coiffier B, Narayanan G et al. Pixantrone dimaleate versus other chemotherapeutic agents as a single-agent salvage treatment in patients with relapsed or refractory aggressive non-Hodgkin lymphoma: a phase 3, multicentre, open-label, randomized trial. Lancet. 2012; 13(7): 696-706.

11. Piksantron w leczeniu chłoniaków złośliwych. https://www.gov.pl/web/zdrowie/choroby-onkologiczne.

12. Warzocha K, Puła B. Rozpoznawanie i leczenie chorych na chłoniaka rozlanego z dużych komórek B. Hematologia. $2017 ; 8(2): 113-31$.

13. Swerdlow SH, Campo E, Piler SA et al. The 2016 revision of the World Health Organization classification of lymphoid neoplasms. Blood. 2016; 127(20): 2375-90.

14. Lenart K, Szyda A, Kiełbasiński M et al. Kliniczne skutki oporności wielolekowej w nowotworach. Onkologia w Praktyce Klinicznej. 2005 ; 1(1): 18-26.

15. Menna P, Salvatorelli E, Minotti G. Rethinking drugs from chemistry to therapeutic opportunities: pixantrone beyond anthracyclines. Chem Res Toxicol. 2016; 29(8): 1270-8.

16. Singal KS, Iliskovic N. Doxorubicin-induced cardiomyopathy. N Engl J Med. 1998; 339(13): 900-5.

17. Salvatorelli E, Menna P, Paz OG et al. The novel anthracenedione, pixantrone, lacks redox activity and inhibits doxorubicinol formation in human myocardium: insight to explain the cardiac safety of pixantrone in doxorubicin-treated patients. J Pharmacol Exp Ther. $2013 ; 344(2)$ : 467-78.

18. Pettengel R, Coiffier B, Egorov A et al. Long-Term Response and Remission with Pixantrone in Patients with Relapsed or Refractory Aggressive Non-Hodgkin Lymphoma: Post-Hoc Analysis of the Multicenter, Open-Label, Randomized PIX301 Trial. Clin Drug Investig. 2018; $38(6): 527-33$.

19. Czerw T. Znaczenie allogenicznego przeszczepienia krwiotwórczych komórek macierzystych w leczeniu chorych na chłoniaki. Hematologia. 2012; 3(1): 49-57.

20. van Besien K. Current status of allogeneic transplantation for aggressive non-Hodgkin lymphoma. Curr Opin Oncol. 2011 ; 23(6): 681-91.

Authors' contributions:

Sebastian Giebel: supervision; Anna Kwiatkowska-Pamuła: case report, discussion, summary, collection and analysis (keeping medical records), summary and bibliography on the above-mentioned parts: Aleksandra Janeczek: introduction, purpose, collecting materials (keeping medical records), graphic, summary and bibliography on the above-mentioned parts.

Conflict of interests:

The authors declare no conflict of interest regarding the publication of this article.

Financial support:

None.

Ethics:

The authors had full access to the data and take full responsibility for its integrity.

All authors have read and agreed with the content of the manuscript as written.

The paper complies with the Helsinki Declaration, EU Directives and harmonized requirements for biomedical journals. 